\title{
Sistemas de indicadores de saúde e ambiente em instituições de saúde
}

\author{
Health and environmental \\ indicator systems in health institutions
}

\author{
Débora Cynamon Kligerman ${ }^{1}$ \\ Heliana Vilela ${ }^{2}$ \\ Telma Abdalla de O liveira C ardoso ${ }^{3}$ \\ Simone Cynamon Cohen ${ }^{1}$ \\ Denise Sousa ${ }^{2}$ \\ Emilio La Rovere ${ }^{2}$
}

\footnotetext{
${ }^{1}$ Departamento de Saneamento, Escola Nacional de Saúde Pública, Fundação O swaldo Cruz. Rua Leopoldo Bulhões $1480,5^{\circ}$ andar,

M anguinhos. 21041-210

Rio de Janeiro RJ.

kliger@ensp.fiocruz.br

${ }^{2}$ COPPE/UFRJ.

${ }^{3}$ Fundação O swaldo Cruz.
}

Abstract This article presents a discussion on conceptual and methodological aspects involved in the establishment of a system of indicators for Health and Environment, with the purpose of integrating the management of research, education and health services institutes whileal so taking Biosafety into account. The initial task was the study of international indicator models, paying special attention to theWorld $\mathrm{H}$ ealth O rganization model, more apropriate to this article, which was used in the process of collection, organization and synthesis of data. This work aims to create methodological instruments for the monitoring and evaluation of these procedures and support the decision making process.

Key words Indicator, Publichealth , Environmental management and biosafety
Resumo N este artigo, é realizada uma revisão teórica sobre aspectos conceituais e metodológicos da construção de um sistema de indicadores, visando a gestão integrada em saúdeeambientenas instituições de pesqui sa, ensino eprestação de serviços em saúde, que articule também a Biossegurança. Partiu-se do estudo de model os internacionais de indicadores, destacando-se o modelo da Organização M undial de Saúde, mais apropriado para este trabalho, a partir do qual foi feito 0 processo de coleta, organização e síntese de informações. Visa-se criar um instrumental de monitoramento eavaliação destas ações, a fim de apoiar a tomada de decisões.

Palavras-chaveIndicador, Saúdecoletiva, Gestão ambiental e biossegurança 
Introdução

A sustentabilidade associada ao desenvolvimento éuma preocupação quevem setornando meta presente no discurso e, de certa forma, nas ações que permeiam as decisões dos gestores públicos e, também, privados. Existe uma clara demanda, especificada inclusive nos vários documentos oriundos das conferências internacionais demeio ambiente, para incorporar a variável ambiental no processo de tomada de decisão, com base no fortalecimento deum modelo dedesenvolvimento que requer uma perspectiva de planejamento a longo prazo, orientado por informações confiáveis, atualizadas e de fácil compreensão.

Para a realização de políticas públicas saudáveis, são necessários mecanismos que tenham como objetivo: a formulação e implementação integrada de políticas e intervenções; responsabilização dos diferentes setores envolvidos nas conseqüências destas políticas sobre a saúde; ações intersetoriais; empowerment da população em torno das políticas e construção de alianças. Atualmente, a idéia sobre as políticas públicas saudáveisédecompromisso político etécnico. 0 compromisso político édesituar a saúdeno topo da agenda pública. 0 compromisso técnico é de enfatizar como foco de intervenção os fatores determinantes do processo saúde-doença.

Nesse contexto, dentro do paradigma da sustentabilidade, que emergiu na Conferência das Nações Unidas sobre o M eio Ambiente e Desenvolvimento, em 1992 (Rio 92), o conceito de produção sustentável podeser enten dido como: "produção e serviços usando processos e sistemas que não poluam, conservando energia e recursos naturais, sejam economicamente viáveis, seguros esaudáveis para os empregados, comunidades e consumidores, recompense socialmente os trabal hadores e estimule a sua criatividade" 1

Para a obtenção de mecanismos de aferição dos progressos obtidos dentro desta produção, são utilizados indicadores, que simplificam e substituem dados muito extensos e textos descritivos por medidas estabelecidas de comum acordo, além de possibilitar a visualização das tendências através do tempo ${ }^{2}$. Os indicadores são propostos como instrumentos de representação da informação, que permitem organizar, sintetizar e utilizar informações, úteis ao planejamento, ao estabelecimento de metas eao controle do desempenho, viabilizando, assim, a análise de decisões estratégicas e a tomada de decisão ${ }^{3}$.

Esteartigo tem como objetivo discutir aspectos conceituais e metodológicos da construção de um sistema de indicadores em saúde ambiental, para serem aplicados na gestão de instituições de saúde. Inicialmente, serão abordados os aspectos conceituais sobre indicadores, seguidos de modelos de representação de informações, chegando ao modelo da Organização Mundial de Saúde (OMS) e relacionando-o à gestão destasinstituições.

\section{Indicadores}

Os indicadores foram desenvolvidos devido à necessidade de tratar a informação, na forma original ou "bruta", de modo a torná-la acessível, permitindo entender fenômenos complexos, tornando-os quantificáveis e compreensíveis de maneira que possam ser analisados, utilizados e transmitidos aos diversos níveis da sociedade, contribuindo com uma adequada planificação das políticas; e avançando na modernização institucional através da otimização do manejo das informações ?.

A Figura 1 sintetiza a forma como se dá o processo de elaboração das informações, realizado deacordo com as diferentes etapas do processo de tomada de decisão, aliado a uma metodologia de sel eção de indicadores determinada pelo modelo conceitual adotado. Verifica-se uma re dução crescente dos dados. $\mathrm{Na}$ base da pirâmide estão os dados brutos que serão analisados e interpretados pelos pesquisadores nos programas de gerenciamento específico e de pesquisa. A seguir, serão transformados em dados a fim desubsidiar os políticos e gestores na tomada de decisões estratégicas e operacionais e, por fim, sintetizados em indicadores, facilitando o processo de socialização das informações.

Os indicadores devem ser os mais específicos possíveis à questão tratada; sensíveis a mudanças específicas nas condições de interesse; cientificamente confiáveis, imparciais e representativos das condições de interesse, além de propiciar o máximo de benefício e utilidade.

Existem al guns critérios que devem ser considerados na seleção de indicadores, que também são aplicáveis aos indicadores de saúde ambiental:

- Existência de dados base;

- Possibilidade de intercalibração;

- N úmero total de indicadores selecionados;

- Tipo de informação transmitida, nomeadamente a natureza da informação (ex. social, física, química ou biológica), os processos funcionais que lhe estão associados no sistema e que tipo de público pode receber essa informação; 
Figura 1

Pirâmide de informação associada ao tipo de utilizador.

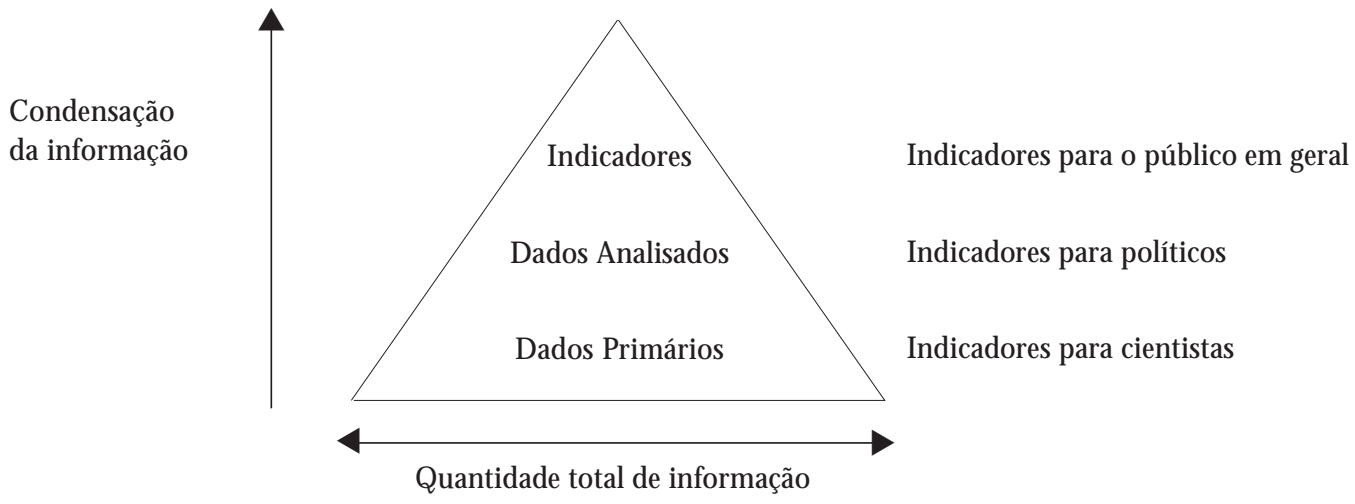

Fonte: Ramos $^{2}$

- Possibilidade de comparação com critérios legais ou outros padrões/metas existentes;

- Custo de implementação; e

- Possibilidade de ser rapidamente atualizado.

\section{Principais modelos}

para construção de indicadores ambientais

Nas décadas de 70 e 80 , os indicadores ambientais começaram a ser utilizados na elaboração e divulgação dos primeiros relatórios sobre 0 estado do ambiente. No final da década de 80 , fol solicitada à Organização para Cooperação Econômica e Desenvolvimento (OCDE $)^{4}$ a identificação e aplicação de um conjunto básico de indicadores ambientais. Esse processo evoluiu e, na Rio 92, já constava da Agenda 21, em seu capítulo 40, a seguinte recomendação:

"Indicadores do Desenvolvimento Sustentável necessitam ser desenvolvidos a fim de proporcionar uma base sólida para a tomada de decisão em todos os níveis e para contribuir para a sustentabilidade auto-regulada do sistema integrado meio ambiente e desenvolvimento".

Foi então desenvolvido o modelo PressãoEstado-Resposta (PER), que se baseia num conceito de causalidade: as atividades humanas exercem pressões sobre o ambiente, modificando sua qualidade e a quantidade de recursos naturais; a sociedade, por sua vez, responde a estas mudanças por intermédio de políticas ambientais, econômicas e setoriais. Esta estrutura está sendo apresentada na Figura 2.

Com o avanço da degradação ambiental. houvenecessidade de incorporar no modelo um elemento que o caracterizasse. Foi, então, introdu- zido o componente "Impacto" no modelo desenvolvido pelo Programa das Nações Unidas e M eio Ambiente (PNUMA) ${ }^{5}$.

O modelo Pressão-Estado-Impacto-Resposta(PEIR) foi utilizado, pelo PNUMA, no programa Geo Cidades. A matriz PEIR define erelaciona o conjunto de fatores que determinam as características atuais do meio ambiente em qualquer nível de agregação territorial (local, regional, nacional, global), buscando estabelecer uma vinculação lógica entre os seus componentes. D efine os padrões de relacionamento entre as ações antrópicas urbanas e o meio ambiente.

Tentando, então, caracterizar, de forma mais abrangente, quais fatores geram estes impactos, a Comissão das Nações Unidas para o Desenvolvimento Sustentável (UNCSD) substituiu o elemento "Pressão" pela "Força M otriz".

A OMS, pensando nos fatores de risco e nos efeitos à saúde humana, substituiu o elemento "Impacto" pelos elementos "Exposição" e "Efeito". Também, o elemento "Resposta" foi substituído por "Ação", refletindo sobre as intervenções que devem ser realizadas a fim de minimizar os perigos à saúde.

Com base no Environmental Health Indicators for Europe, a OM S propôs um modelo conceitual denominado DPSEEA (Figura 3): Força Motriz - Pressão - Estado - Exposição - Efeitos - Ações, que retrata um sistema de indicadores de saúde ambiental , para descrever e analisar a ligação entre saúde, meio ambiente e desenvolvimento e tem sido usado na análise da situação global, como subsídio à tomada de decisão.

Este é um modelo no qual forças motrizes geram pressões que modificam o estado no 
Figura 2

Estrutura PER para organização e apresentação de informação ambiental.

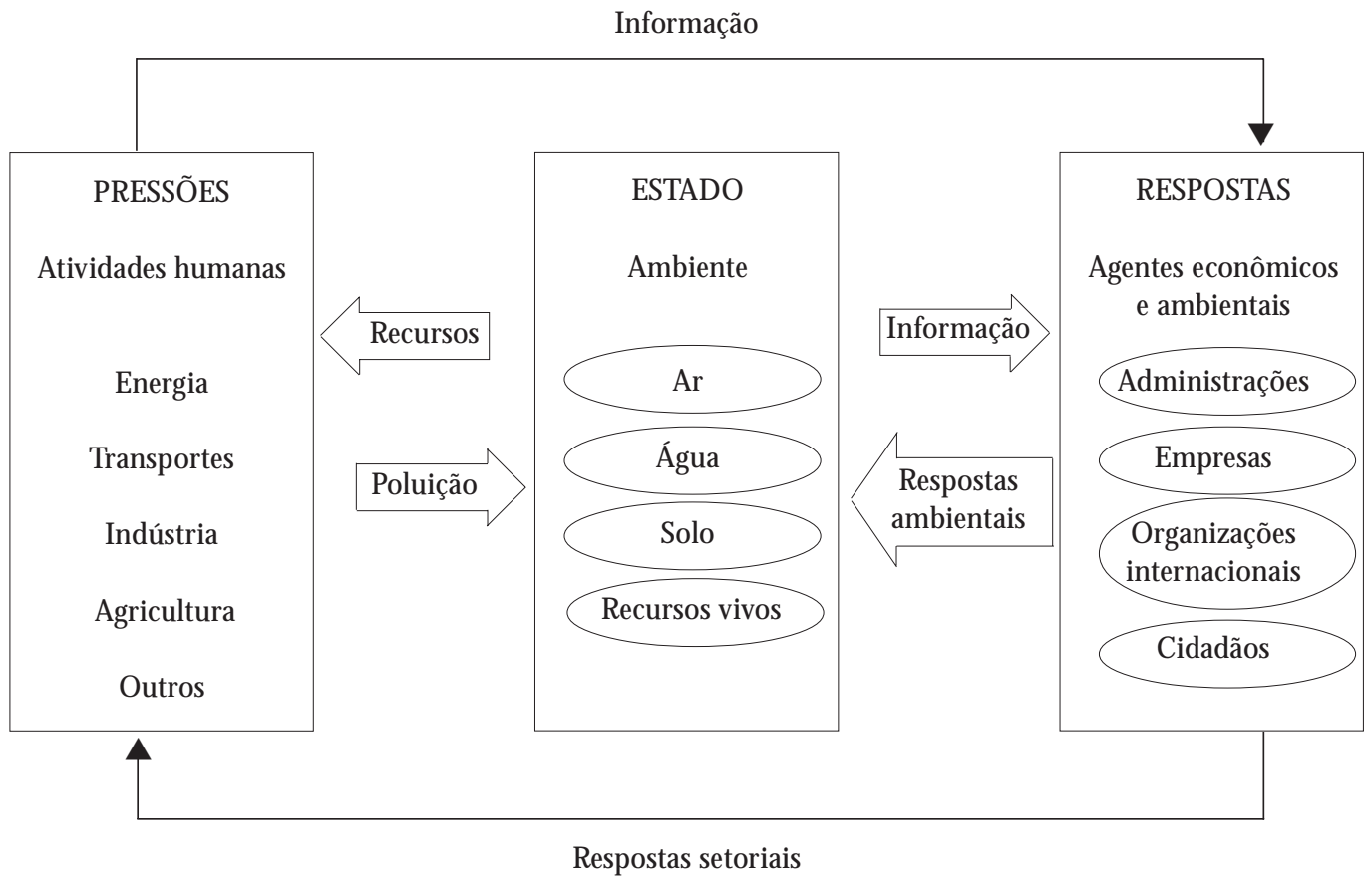

Fonte: PNUMA ${ }^{5}$.

Figura 3

Exemplo de indicadores e sua associação ao modelo DPSEEA.

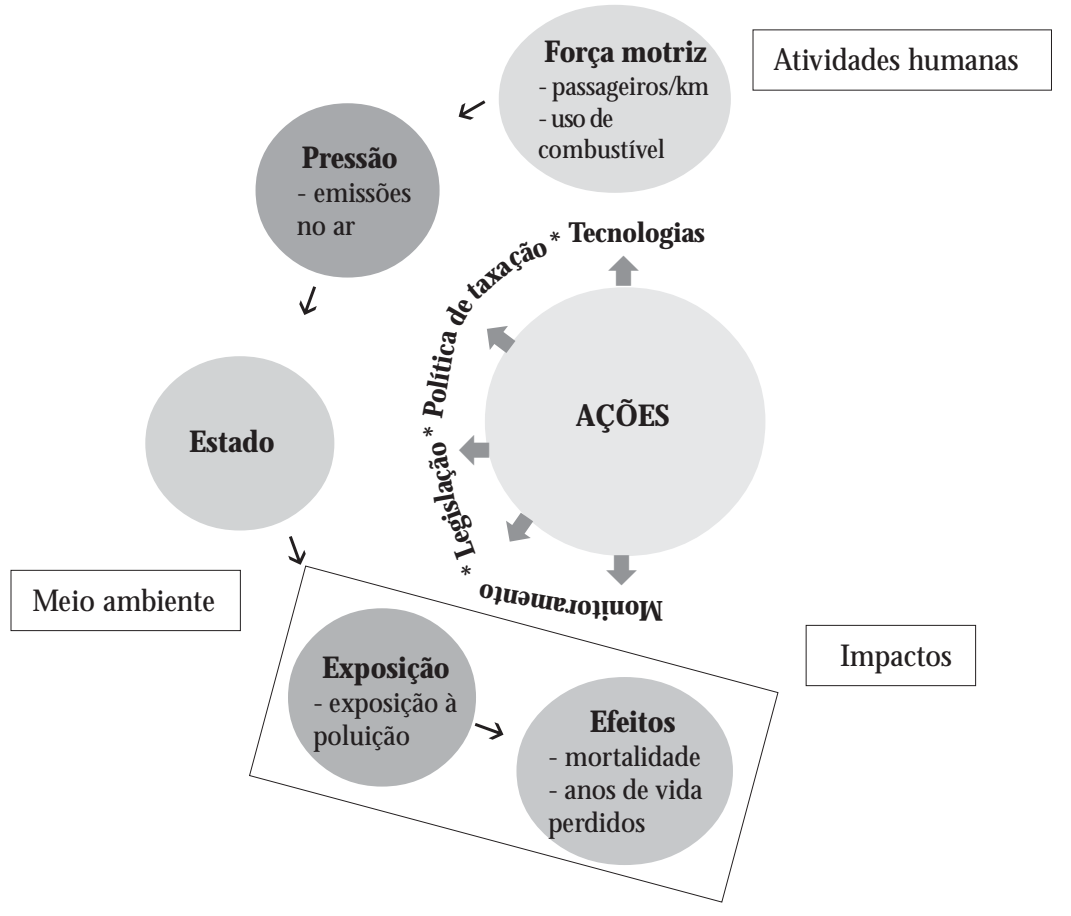


ambiente ea saúde humana, por meio das diversas formas de exposição a riscos, ocasionados por condições adversas, causando efeitos à saúde.

Segundo Giral do et al ${ }^{6}$, o M inistério da Saúde entende que através do modelo da OM S, DPSEEA, ou em português FPEEEA, podem ser integradas as análises dos efeitos dos riscos ambientais ao desenvolvimento eimplementação de processos decisórios, políticas públicas e práticas de gerenciamento de riscos.

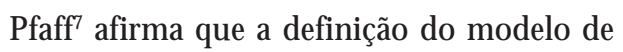
sistema de indicadores é uma opção paradigmática e, portanto, "deve ser definido deforma mais ampla como um modelo de controle", assumindo assim uma função estratégica, pois há um comprometimento com mudanças reais e étambém articulado com a dinâmica da produção da realidade.

Os problemas ambientais atuais e seus conseqüentes efeitos à saúde necessitam ser discutidos pela sociedade a fim degerar, adotar eimple mentar uma gama de ações corretivas e preventivas. Estas ações devem ser tomadas com a finalidade de minimizar ou controlar os riscos e introduzindo medidas de controle e de monitoramento. As ações de longo prazo mais efetivas, entretanto, são aquelas que abordam o tema de maneira preventiva, visando diminuir ou eliminar as forças motrizes.

Borja et al. ${ }^{8}$ avaliam que a discussão sobre os indicadores serem qualitativos ou quantitativos repousa em olhares distintos mas, segundo os autores, "representam formas diferentes, complementares e não antagônicas, de estudar um fenômeno" econcluem que deve haver interação entre estas duas abordagens.

M odelo Força M otriz-Pressão-EstadoExposição-Efeito-Ação (FPEEEA) a ser aplicado em instituições de saúde

De acordo com Delduque et al. ${ }^{9}$, a questão da qualidade ambiental é abordada na Constituição Federal de 1988, artigo 225, quando se refere que "todos têm direito ao meio ambiente ecologicamente equilibrado, bem de uso comum do povo e essencial à sadia qualidade de vida, impondo-seao poder público eà coletividadeo dever de defendêlo e preservá-lo para as presentes e futuras gerações." Segundo estes autores, a forma como é expressa a qualidade ambiental no texto legislativo é híbrida, pois coloca "ao lado da conservação e salvaguarda dos recursos naturais a saúde humana". Sob este ponto de vista, os indicadores queservem para monitorar a qualidade ambiental também atuam na proteção da saúde humana.

Segundo Borja et al. ${ }^{10}$, uma das primeiras aplicações do modelo de sistema de indicadores FPEEEA na área desaúdefoi observada em 1998, no texto da OM S intitulado Indicadores para 0 Estabelecimento de Políticas e a Tomada de Decisão em Saúde Ambiental, com o objetivo de fundamentar a área de vigilância ambiental.

Dando continuidade a este trabal ho, a Coordenação Geral deVigilânciaAmbiental (CGVAM), da Secretaria de Vigilância em Saúde (SVS), do M inistério da Saúde ${ }^{11}$, com o apoio da Organização Pan-americana de Saúde, vem discutindo o modelo de sistema de indicadores da OMS, FPEEEA, para a definição de indicadores para monitorar a água de consumo humano. A partir daí, criou o VIGIÁGUA e o SISÁGUA, que são, respectivamente, programa de vigilância e sistema de informações da qual idade da água deconsumo humano, que vão ao encontro ao que Giraldo et al. ${ }^{6}$ enfatizaram, ou seja, a necessidade de uma política de informação em saúde ambiental "capaz de monitorar as políticas públicas, os processos produtivos e todas as atividades econômicas, bem como as ações de interven ção que visem melhorar as condições ambientais e de saúde das populações". Para isto, os gestores têm se esforçado no estabelecimento de indicadores "que sirvam de base para as medidas normativas e gerenciais". Borja et al..$^{10}$ dão como exemplos outras aplicações em sistemas de informação em Saneamento. N este trabalho, portanto, há o estabelecimento de um conjunto de indicadores e sua apresentação no formato do modelo FPEEEA para ser aplicado em instituições de saúde. Foram selecionados indicadores em quatro temas: ar, água, solo e saúde do trabalhador. Visa-se o monitoramento e avaliação dos impactos causados pelas atividades destas instituições na saúde ambiental. Para esta seleção, tem-se que, primeiro, entender a organização e a produção das instituições de saúde.

As instituições de saúde são, portanto, ambientes singulares, diferenciados de outros espaços laborais, devido à complexidade de suas ações, que vão desdea assistência à população, verificação da qualidade dos produtos expostos ao consumo da população, até o diagnóstico laboratorial de amostras biológicas de doenças de interesse para a saúde coletiva. Além disto, diferentes fatores devem ser considerados nos estudos de saúde ambiental, que estão relacionados ao manuseio de diferentes agentes derisco eao próprio trabalhador. 
Somente um enfoque multidisciplinar com ações interdisciplinares poderá centrar iniciativas que permitam conhecer e controlar os riscos que o trabal ho científico destas instituições pode aportar ao ambiente e a vida. No que se refere, em especial, à aplicação prática da Biossegurança e suas interfaces com a Gestão Ambiental, essa preocupação está voltada à instauração de sistemas de preven ção e controle baseados na avaliação de risco e nas respectivas normas para contenção destes, permitindo, assim, que seja estabelecido o nível de contenção exigido para o trabalho seguro. 0 fator "risco" éum dos principais argumentos que fundamentam os programas e as políticas de prevenção.

No Dicionário de Epidemiologia12, o verbete risco faz menção à probabilidade de ocorrência deum evento (mórbido ou fatal). Para Conway ${ }^{13}$, risco é definido como a medida da probabilidade e da severidade de efeitos adversos. Esta definição de risco está calçada na abordagem dos fatores que os causam, isto é, marcadores que levam a alterações anátomo-patológicas futuras $^{14}$. Portanto, estes fatores, mesmo sendo mensuráveis, podem estar explícitos ou evidentes; porém, há outros quesão invisíveis, ou seja, imperceptíveis por sinais/sintomas. A medicina passa a incorporar como atribuição a localização eidentificação dos indivíduos (humanos ou animais) sadios e seus possíveis riscos (oriundos de modalidades de exposição ambiental e/ou de susceptibilidades biológicas, mediante técnicas diagnósticas cada vez mais refinadas). Surge uma rede de riscos em que comportamentos, estilos de vida, consumo de substâncias, sinais, sintomas e doenças podem confluir para se tornarem fatores de risco para um evento em saúde.

No contexto das instituições de saúde, a gestão de riscos deve ser uma das ações de uma política ou programa de proteção e recuperação da saúde ${ }^{15}$. Para esta gestão, a avaliação de riscos se torna uma ferramenta de importância, na medida em que identifica os agentes de risco, possibilitando a determinação dos indicadores que serão utilizados na tomada de decisão e nas estratégias de ações preventivas, que fazem parte da gestão da Biossegurança nas instituições de saúde.

Deve-se destacar queesteartigo utiliza o conceito ampliado de Biossegurança, utilizado pelo Ministério da Saúde ${ }^{16}$, ou seja, "a condição de segurança alcançada por um conjunto de ações destinadas a prevenir, controlar, reduzir ou eliminar riscos inerentes às atividades que possam comprometer a saúde humana, animal e vegetal e o meio ambiente".
Essas ações contemplam várias aspectos re lativos a procedimentos (boas práticas laboratoriais: padrões eespeciais), à infra-estrutura (desenho, instalações físicas eequipamentos de proteção), à qualificação das equipes, à organização do trabal ho (atividades monótonas, repetitivas, estressantes) e a aspectos ambientais (qualidade do ar, água, solo).

Nas instituições de saúde, durante o processo de planejamento das edificações, a arquitetura utiliza o espaço físico como um instrumento de contribuição, tanto para a confiabilidade dos resultados dos ensaios realizados, como para a proteção da saúde humana, animal e do meio ambiente.

Do ponto devista histórico, pouca experiência era demonstrada no desenho e qualidade ambiental destes locais detrabalho; entretanto, a busca pelo conforto e qualidade ambiental de uma instalação foi sendo introduzida e consolidada por novas áreas de conhecimento, incluindo a Biossegurança. Esta evolução leva ao aparecimento de novas diretrizes nas áreas de arquitetura, engenharia edesenho industrial, modificando concepções de espaços, materiais de acabamento, mobiliário e de equipamentos, dentre outros aspectos, que contribuem para a minimização dos eventuais riscos relacionados às atividades e/ou suas aplicações nas instituições de saúde.

Exemplificando esta evolução, pode-se citar a experiência da Síndrome do Edifício Doente, reconhecida pela Organização Mundial de Saú$\mathrm{de}^{17}$ em 1982, quando se comprovou a contaminação do ar interno de um hotel na Filadélfia, Estados Unidos. Este episódio éimportante, pois amplia a discussão da existência de fatores relacionados ao ambiente nos agravos à saúde de seus ocupantes, anteriormente focada somente nos espaços laborais para outros espaços, como por exemplo, os de moradia.

A "Síndrome do Edifício Doente" refere-se à relação entre causa e efeito das condições ambientais observadas em áreas internas, com reduzida renovação de ar, e os vários níveis de manifestações agudas de saúde e de conforto ambiental de seus ocupantes através de fontes poluentes de origem física, química e/ou microbiológica. São considerados "edifícios doentes" todos aqueles edifícios em que mais de vinte por cento dos ocupantes revelariam sintomatologias transitórias associados ao tempo de permanência em seu interior, que tenderiam a desaparecer após curtos períodos de afastamento.

Nesse contexto, a estrutura dos indicadores aplicável às instituições de saúde deve ter uma visão de saúde e ambiente; por este motivo, escoIheu-se o modelo apresentado da OMS, o FPEE- 
EA. A matriz de causa e efeito proposta pela OM S é representada pela cadeia intitulada desenvolvimento-meio ambiente-saúde, que revela o entendimento de que a saúdeéo resultado da interação entre desenvolvimento emeio ambiente.

A Tabela 1 apresenta alguns indicadores de Saúde e Ambiente, subsidiados pela Biossegurança, que poderão ser utilizados em instituições de saúde. Esta tabela é uma adaptação de La Rovere et al. ${ }^{18}$ e foi desenvolvida após consulta à Rede Interagencial de Informações para a Saú$\mathrm{de}^{19}$, Secretaria $\mathrm{N}$ acional de Saneamento Ambiental ${ }^{20}$, Cities Environment Reports on the Internet ${ }^{21}$, Instituto Brasileiro de Geografia e Estatística ${ }^{22}$, O rganización Panamericana de La Salud ${ }^{23}$, The World Bank ${ }^{24}$, United Nations Human Settlements Programme ${ }^{25}$, World Health O rganization ${ }^{26}$ e aos indicadores apontados por M assei ${ }^{27}$.

É importante enfatizar que não se pretende esgotar o temaesim subsidiar a definição deum elenco mínimo deindicadorescomuns a todososníveis.

0 modelo mostra que, para a construção dos indicadores, é primordial a definição do problema ou da questão a ser abordada, a partir do uso destes indicadores e do interesse do pesquisador. Pode-se citar alguns aspectos que devem ser considerados: o risco específico, o local onde ocorre a exposição, o resultado específico à saúde, a ação específica ou a força condutora adjacente relacionada, principalmente ao trabalhador (como, por exemplo, as condições precárias de vida ou o comprometimento imunológico).

É importante destacar que os indicadores só poderão ser elaborados com a disponibilização de informações e estas devem expressar a realidade das ações nas unidades para que se possam analisar os fatores que estão contribuindo ou gerando "efeitos" na saúde dos profissionais destas instituições e que merecem uma "ação".

A definição de procedimentos para a avaliação de saúde e ambiente é muito importante na determinação das causas e na avaliação dos agravos em saúde ligados às contaminações, condições ambientais e de vida do trabalhador. Para tanto, o conhecimento das condições ambientais locais e das atividades érelevante para o estabelecimento de medidas de preven ção aos agravos e a eliminação dos riscos potenciais e existentes.

D estaca-se a necessidade na definição eidentificação dos dados a serem levantados em relação a cada indicador, assim como a fonte de dados. Pode haver o surgimento de problemas de diversas naturezas, como por exemplo: a falta de dados a nível local; disponibilidade de dados em intervalos de tempo inadequados ou insuficientes para determinar tendências espaci- ais ou temporais; dificuldade de local izar dadas condições do meio ambiente e de saúde; dentre outros; tornando difícil a criação de vínculos entre as condi ções ambientais e as condi ç̧ões de saúde, ou a identificação de grupos de risco. Além disto, o componente subjetivo deve ser incorporado, pois está relacionado à percepção de quem vivencia a realidade que se quer avaliar, influenciada por aspectos culturais, econômicos, físicos e sociais.

Por fim, é importante enfatizar que a construção de indicadores cumpre um objetivo espeć́fico da avaliação da relação saúde e ambiente, mas não éa única maneira de avaliá-la. Os mesmos se constituem em instrumentos quefacilitam a leitura da realidade.

\section{Consideraçõesfinais}

Os desafios trazidos pelo uso de novas tecnologias, ocasionando efeitos sobre a saúde e que são relacionados ao meio ambiente, se transformam em uma preocupação cada vez mais complexa e abrangente, acarretando uma reflexão sobre a necessi dade de mecanismos informacionais com qualidade, que subsidiem esta nova forma de pensar e abordar os problemas. Este trabalho, em face da complexidade da questão, busca estimular a interdisciplinaridade para a obtenção do entendimento e a compreensão das relações entrea saúde eambiente, propiciando e garantindo o êxito na definição dosindicadores pelaintegração das três áreas, Gestão Ambiental, Biossegurança e Saúde do Trabalhador no sentido do compartilhamento de dados e de informações.

Neste trabalho, foram apresentados modelos de construção de indicadores e identificou-se como modelo ideal a ser a empregado em instituições de saúde o modelo da World Health Organization ${ }^{28}$, com os elementos Força M otrizPressão-Estado-Exposição-Efeito-Ação, modelo que propõe um conjunto de indicadores de saúde eambiente visando monitorar o desempenho destas instituições em relação a seus objetivos e metas, contribuindo para a melhoria contínua dos seus processos organizacionais.

A expectativa com relação a este trabalho éa de que as instituições de saúde possam implementar um conjunto de indicadores compatível com sua função social podendo, paralelamente, ser ponto focal para iniciativas semelhantes no âmbito do setor de Ciência e Tecnologia. Dessa forma, os indicadores conformariam políticas públicas saudáveis pró-ativas com o compromisso político etécnico. 
Tabela 1

Indicadores de saúde, biossegurança e ambiente para instituições de saúde.

\begin{tabular}{|c|c|c|c|c|c|}
\hline \multicolumn{6}{|c|}{ Tema: ar } \\
\hline Força M otriz & Pressão & Estado & Exposição & Efeito & A ção \\
\hline $\begin{array}{l}\text { Força de } \\
\text { trabalho } \\
\text { Ambiente } \\
\text { construído: } \\
\text { - unidades } \\
\text { produtivas } \\
\text { - unidades } \\
\text { administrativas } \\
\text { - unidades } \\
\text { assistenciais } \\
\text { - unidades } \\
\text { laboratoriais } \\
\text { de pesquisas } \\
\text { - outras } \\
\text { unidades }\end{array}$ & 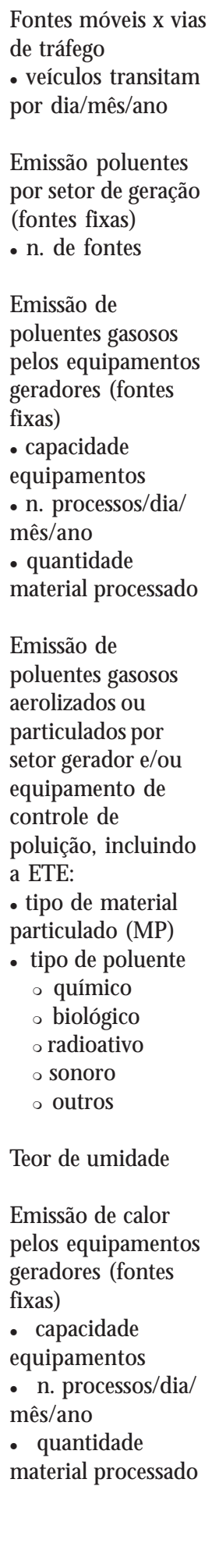 & $\begin{array}{l}\text { Qualidade do } \\
\text { ar por agentes } \\
\text { poluidores: } \\
\text { - químicos } \\
\text { - biológicos } \\
\text { - físico } \\
\text { - radioativo } \\
\text { Violação dos } \\
\text { padrões de } \\
\text { qualidade do } \\
\text { ar por } \\
\text { elemento } \\
\text { poluidor (S/ } \\
\text { N) } \\
\text { Nível de: } \\
\text { - ruído } \\
\text { - radiação nas } \\
\text { unidades } \\
\text { geradoras } \\
\text { - umidade } \\
\text { relativa do ar } \\
\text { - temperatura } \\
\text { ambiente } \\
\text { - diferencial } \\
\text { de pressão } \\
\text { - iluminação } \\
\text { natural e } \\
\text { artificial } \\
\text { Taxa de } \\
\text { renovação do } \\
\text { ar } \\
\text { M anutenção } \\
\text { do sistema de: } \\
\text { (periodicidadel } \\
\text { ano) } \\
\text { - climatização } \\
\text { - luminação } \\
\text { - ar } \\
\text { M anutenção } \\
\text { dos } \\
\text { equipamentos } \\
\text { de proteção } \\
\text { (periodicidadel } \\
\text { ano) }\end{array}$ & $\begin{array}{l}\text { N. de } \\
\text { trabalhadores } \\
\text { que } \\
\text { manuseiam: } \\
\text { - agentes de } \\
\text { risco químico } \\
\text { - agentes de } \\
\text { risco biológico } \\
\text { - radioisótopos } \\
\text { N. } \\
\text { trabalhadores } \\
\text { expostos a: } \\
\text { - temperatura } \\
\text { anormais } \\
\text { - níveis de } \\
\text { ruído acima do } \\
\text { permitido } \\
\text { - taxas } \\
\text { inadequadas de } \\
\text { umidade } \\
\text { - radiação } \\
\text { N. de pessoas } \\
\text { (visitantes, } \\
\text { alunos, etc) } \\
\text { expostos a: } \\
\text { - agentes de } \\
\text { risco químico } \\
\text { - agentes de } \\
\text { risco biológico } \\
\text { - radiação } \\
\text { - temperaturas } \\
\text { anormais } \\
\text { - níveis } \\
\text { inadequados de } \\
\text { ruído } \\
\text { - taxas } \\
\text { inadequadas de } \\
\text { umidade }\end{array}$ & $\begin{array}{l}\text { Taxa de absenteísmo } \\
\text { relacionado à: } \\
\text { - poluição do ar } \\
\text { - poluição sonora } \\
\text { - por stress } \\
\text { Taxa de incidência de } \\
\text { doenças: } \\
\text { - doenças } \\
\text { respiratórias } \\
\text { - doenças infecciosas } \\
\text { - distúrbios auditivos } \\
\text { - distúrbios visuais } \\
\text { - distúrbios } \\
\text { neurológicos } \\
\text { - distúrbios } \\
\text { psicológicos } \\
\text { - incidência de } \\
\text { tumores } \\
\text { - distúrbios } \\
\text { dermatológicos } \\
\text { - queimaduras; } \\
\text { - outras doenças ou } \\
\text { distúrbios } \\
\text { N. delicenças } \\
\text { médicas por doenças } \\
\text { ocupacionais } \\
\text { relacionadas } \\
\text { Despesas com a saúde } \\
\text { devido às doenças } \\
\text { ocupacionais } \\
\text { relacionadas } \\
\text { N. de acidentes com } \\
\text { exposição a aerossóis } \\
\text { N. de acidentes com } \\
\text { exposição a vapores } \\
\text { químicos }\end{array}$ & $\begin{array}{l}\text { M onitoramento de } \\
\text { emissões de fontes } \\
\text { fixas } \\
\text { Programa de } \\
\text { manutenção predial e } \\
\text { de equipamentos } \\
\text { Investimento em } \\
\text { monitoramento da } \\
\text { qualidade do ar } \\
\text { Investimentos no } \\
\text { controle da qualidade } \\
\text { do ar } \\
\text { Investimentos em } \\
\text { monitoramento de } \\
\text { ruído nas áreas } \\
\text { geradoras } \\
\text { Investimentos no } \\
\text { controle dos níveis de } \\
\text { ruídos nas áreas } \\
\text { geradoras } \\
\text { Investimentos no } \\
\text { controle dos níveis de } \\
\text { radiação nas áreas } \\
\text { geradoras } \\
\text { Investimentos em } \\
\text { programas de } \\
\text { prevenção de } \\
\text { acidentes } \\
\text { Programas de } \\
\text { Educação Ambiental } \\
\text { relacionados a ruídos } \\
\text { eà qualidade do ar } \\
\text { (indoor e outdoor) } \\
\text { Inaras }\end{array}$ \\
\hline
\end{tabular}


Tabela 1

continuação

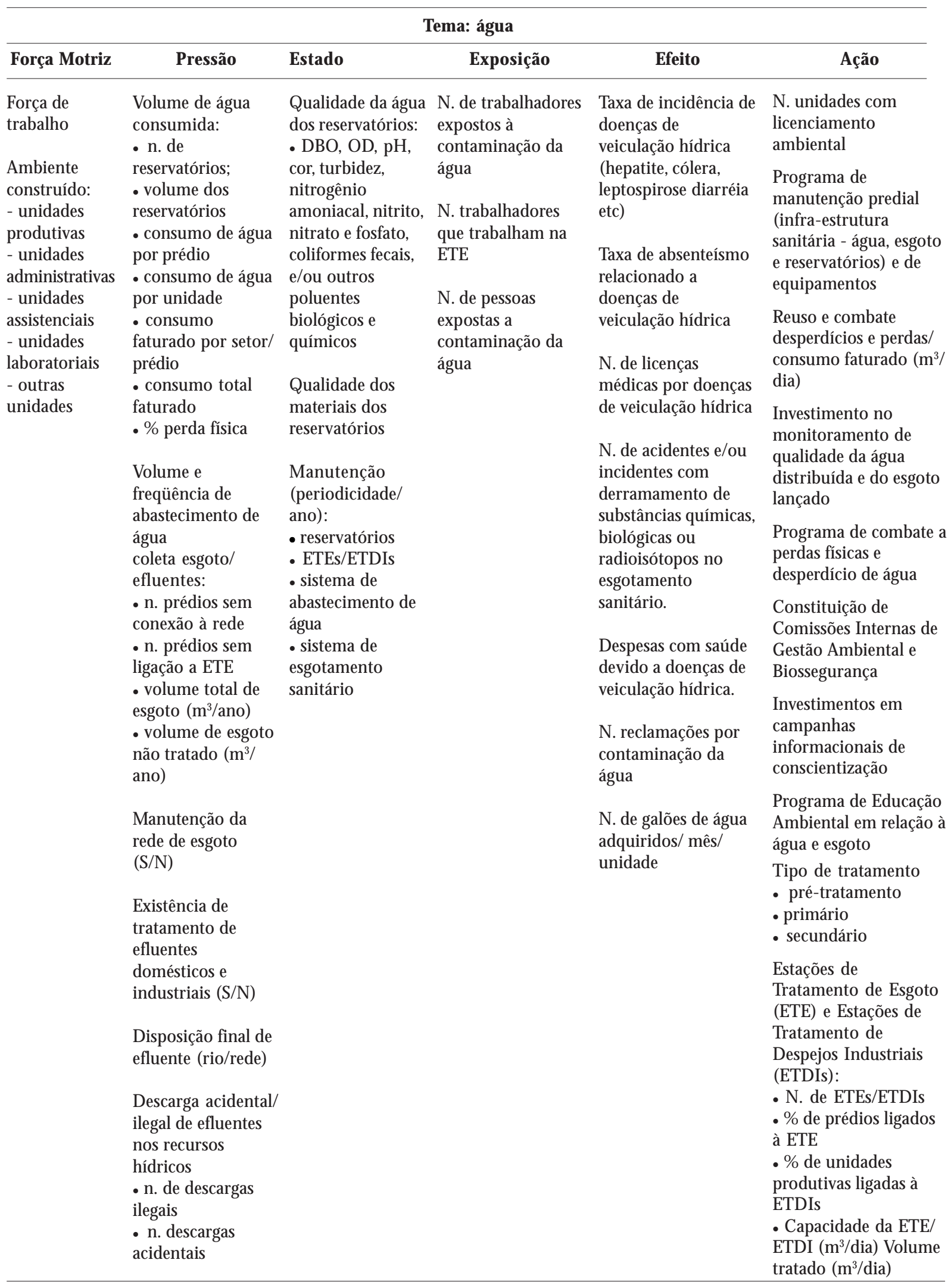


Tabela 1

continuação

\begin{tabular}{|c|c|c|c|c|c|}
\hline \multicolumn{6}{|c|}{ Tema: solo } \\
\hline Força M otriz & Pressão & Estado & Exposição & Efeito & Ação \\
\hline $\begin{array}{l}\text { Força de } \\
\text { trabalho } \\
\text { Ambiente } \\
\text { construído: } \\
\text { - unidades } \\
\text { produtivas } \\
\text { - unidades } \\
\text { administrativas } \\
\text { - unidades } \\
\text { assistenciais } \\
\text { - unidades } \\
\text { laboratoriais } \\
\text { - outras } \\
\text { unidades }\end{array}$ & $\begin{array}{l}\text { Ocupação } \\
\text { - área ocupada } \\
\text { - \% de ocupação } \\
\text { Quantidade de } \\
\text { resíduos gerados } \\
\text { (ton, kg, litros, ou } \\
\text { m³/dia/semana/ } \\
\text { mês/ ano/prédio/ } \\
\text { unidade } \\
\text { geradora): } \\
\text { - químico, } \\
\text { - radioativo, } \\
\text { - biológico, } \\
\text { - perfurocortantee } \\
\text { - comum } \\
\text { Existência de } \\
\text { tratamento } \\
\text { interno e externo } \\
\text { de resíduos? } \\
\text { (S/N) } \\
\text { Percentual de } \\
\text { resíduos não } \\
\text { tratados ( por tipo } \\
\text { de resíduo) } \\
\text { \% de resíduos } \\
\text { incinerados (por } \\
\text { tipo de resíduo) } \\
\text { Nível de } \\
\text { adensamento } \\
\text { (proximidades de } \\
\text { unidades não } \\
\text { respeitando a } \\
\text { estrutura } \\
\text { hidrogeológica do } \\
\text { solo) }\end{array}$ & $\begin{array}{l}\text { Contaminação } \\
\text { do solo por } \\
\text { agentes } \\
\text { poluidores: } \\
\text { - químicos } \\
\text { - biológicos e } \\
\text { - radioativos } \\
\text { \% área verde/ } \\
\text { ambiente } \\
\text { construído } \\
\text { Estado } \\
\text { (condições) do } \\
\text { ambiente } \\
\text { construído }\end{array}$ & $\begin{array}{l}\text { N. de trabalhadores } \\
\text { que manuseiam } \\
\text { resíduos: } \\
\text { - químicos, } \\
\text { - biológicos, } \\
\text { - perfurocortantese } \\
\text { - radioativos } \\
\text { N. de pessoas } \\
\text { expostas a resíduos }\end{array}$ & $\begin{array}{l}\text { N. áreas contaminados } \\
\text { por armazenamento } \\
\text { irregular de resíduos } \\
\text { Alteração do uso do } \\
\text { solo estabelecido no } \\
\text { Plano Diretor do } \\
\text { Campus (S/N) } \\
\text { N. reclamações devido } \\
\text { a: } \\
\text { - armazenamento } \\
\text { temporário de resíduos } \\
\text { - proliferação de } \\
\text { vetores (insetos e } \\
\text { roedores) } \\
\text { - descarte inadequado } \\
\text { de resíduos } \\
\text { Taxa de incidência de } \\
\text { doenças devido à } \\
\text { manipulação de } \\
\text { resíduos: } \\
\text { - doenças infecciosas } \\
\text { - doenças respiratórias } \\
\text { - distúrbios } \\
\text { dermatológicos } \\
\text { - distúrbios } \\
\text { neurológicos } \\
\text { - distúrbios } \\
\text { psicológicos } \\
\text { - incidência de tumores } \\
\text { - outras doenças ou } \\
\text { mistúrbios } \\
\text { resíduos } \\
\text { relacionadadas } \\
\text { Taxa de absenteísmontes devido à } \\
\text { relacionado às doenças } \\
\text { relacionadas } \\
\text { N. delicenças médicas } \\
\text { por doenças } \\
\text { ocupacionais } \\
\text { relacionadas } \\
\text { Despesas com saúde } \\
\text { devido a doenças } \\
\text { ocupacionais } \\
\text { de de }\end{array}$ & $\begin{array}{l}\text { Revisão e atualização } \\
\text { do Plano Diretor } \\
\text { Investimento na } \\
\text { conservação das áreas } \\
\text { verdes } \\
\text { Programa de } \\
\text { manutenção predial e } \\
\text { de equipamentos } \\
\text { Plano de } \\
\text { Gerenciamento de } \\
\text { Resíduos } \\
\text { - sistema de } \\
\text { tratamento de resíduos } \\
\text { - monitoramento do } \\
\text { descarte de resíduos } \\
\text { - monitoramento do } \\
\text { tratamento interno dos } \\
\text { resíduos } \\
\text { - coleta seletiva e na } \\
\text { reciclagem dos resíduos } \\
\text { - construção de um } \\
\text { centro de } \\
\text { compostagem de } \\
\text { resíduos comuns } \\
\text { - tipo de tratamento } \\
\text { interno e externo dado } \\
\text { aos resíduos gerados } \\
\text { (por tipo de resíduo) }\end{array}$ \\
\hline
\end{tabular}

continua 
Tabela 1

continuação

\begin{tabular}{|c|c|c|c|c|c|}
\hline \multicolumn{6}{|c|}{ Tema: saúde do trabalhador } \\
\hline Força Motriz & Pressão & Estado & Exposi ção & Efeito & Ação \\
\hline $\begin{array}{l}\text { Força de } \\
\text { trabalho } \\
\text { Ambiente } \\
\text { construído: } \\
\text { - unidades } \\
\text { produtivas } \\
\text { - unidades } \\
\text { administrativas } \\
\text { - unidades } \\
\text { assistenciais } \\
\text { - unidades } \\
\text { laboratoriais } \\
\text { - outras } \\
\text { unidades }\end{array}$ & $\begin{array}{l}\text { Total de recursos } \\
\text { humanos (prédio/ } \\
\text { Unidade) } \\
\text { - n. servidores } \\
\text { - n. trabalhadores } \\
\text { comissionados } \\
\text { - n. terceirizados } \\
\text { - n. cooperativados } \\
\text { - n. seguranças } \\
\text { - n. registro } \\
\text { profissional } \\
\text { autônomo } \\
\text { - n. bolsistas } \\
\text { N. de alunos: } \\
\text { - n. de alunos 2oo } \\
\text { grau } \\
\text { - n. de alunos } \\
\text { pós-graduação } \\
\text { (lato sensu/strictu } \\
\text { sensu) } \\
\text { - n. estagiários } \\
\text { N. visitantes/dia/ } \\
\text { mês/ano/prédio/ } \\
\text { Unidade } \\
\text { N. pacientes/dia/ } \\
\text { mês/ano/prédio/ } \\
\text { Unidade }\end{array}$ & $\begin{array}{l}\text { M anutenção } \\
\text { do sistema de } \\
\text { vigilância em } \\
\text { saúde } \\
\text { (periodicidade/ } \\
\text { ano/ } \\
\text { quantitativo) } \\
\text { - exame } \\
\text { médico } \\
\text { periódico } \\
\text { - imunização } \\
\text { Tipo de } \\
\text { imunização } \\
\text { - por área } \\
\text { - por atividade } \\
\text { M anutenção } \\
\text { do controle } \\
\text { sorológico da } \\
\text { imunização } \\
\text { (S/N) }\end{array}$ & $\begin{array}{l}\text { N. de trabalhadores } \\
\text { expostos à } \\
\text { violência } \\
\text { N. de trabalhadores } \\
\text { submetidos a: } \\
\text { - assédio moral } \\
\text { - assédio sexual } \\
\text { N. de trabalhadores } \\
\text { recebedores de } \\
\text { adicional de: } \\
\text { - periculosidade } \\
\text { - insalubridade } \\
\text { N. de trabalhadores } \\
\text { que executam } \\
\text { jornadas noturnas } \\
\text { de trabalho } \\
\text { N. de trabalhadores } \\
\text { com regime de } \\
\text { plantão } \\
\text { Percentual de } \\
\text { trabalhadores } \\
\text { expostos a agentes } \\
\text { de risco: } \\
\text { - biológico } \\
\text { - químico } \\
\text { - acidentes } \\
\text { - físico } \\
\text { o ruído } \\
\text { o radiação } \\
\text { o temperaturas } \\
\text { anormais }\end{array}$ & 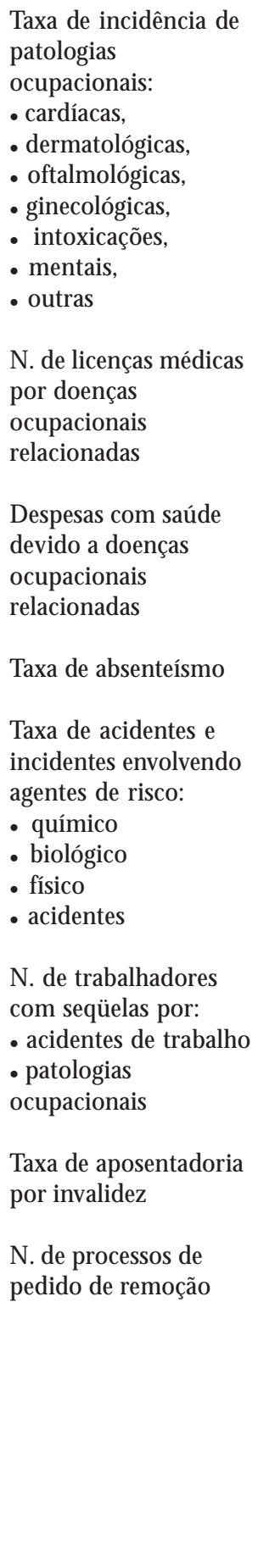 & 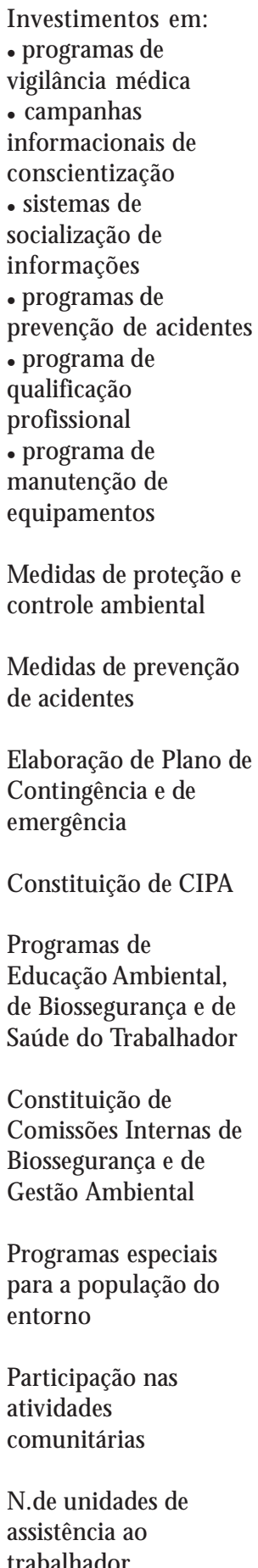 \\
\hline
\end{tabular}




\section{Colaboradores}

DC Kligerman, H Vilela, TA de O Cardoso, SC Cohen trabalharam na concepção, redação e revisão crítica. Todos os autores participaram da pesquisa, metodologia e processo de aprovação da versão a ser publicada.

\section{Referências}

1. Marinho MMO, Andrade JCS, Cardoso LF, Salatie M. Relatório sócioambiental corporativo e produção sustentável. Salvador: Universidade Federal da Bahia UFBA/TECLIM ; 2002.

2. Ramos TB. Sistemas de indicadores e índices ambientais [comunicação]. 40 Congresso Nacional dos Engenheiros do Ambiente. Portugal: APEA; 1997. p. IV33-IV 43.

3. Mousinho PO. Indicadores de desenvolvimento sustentável: modelos internacionais e especificidades do Brasil [dissertação]. Rio de Janeiro (RJ): IBICT, Universidade Federal do Rio de Janeiro; 2001.

4. Organization for Economic Co-operation and Development (OECD). Better Understanding Our Cities: The Role of Urban Indicators, EEA Indicator Set. Paris: OECD; 1997.

5. Programa das Nações Unidas e M eio Ambiente (PNUMA). Directorate General Environment, Working Group of the Expert Group on the Urban Environment, Towards a Local Sustainability Profile - European Common Indicators; 2000.

6. Giraldo LSA, Branco A. Política de informação em saúde ambiental. Revista Brasileira de Epidemiologia 2003; 6(2).

7. Pfaff M. Supervisión y Evaluación del proceso de Crescimiento y Desarrollo Urbanos. In: Naciones Unidas, Indicadores de La Calidad del Desarrollo Urbano. Informe de la Reunión del Grupo Especial de Expertos. Nueva York: Departamento de Asuntos Económicos y Sociales; 1975.
8. Borja PC, M oraes LRS. Indicadores de saúde ambiental com enfoque para a área de saneamento aspectos conceituais e metodológicos. Revista de Engenharia Sanitária e Ambiental 2003; 8 (2): 13-25.

9. Delduque MC, Teixeira AC, Bessa LFM. Aspectos Legais da Transgenia no Brasil e a Qualidade Ambiental. Texto integrante do Programa de Pós-Graduação Stricto Sensu em Planejamento e Gestão Ambiental da Universidade Católica de Brasília; 2005. [acessado 2005 Abr 16]. Disponível em: http:// www.iieb.org.br

10. Borja PC, M oraes LRS. Indicadores de saúde ambiental com enfoque para a área de saneamento estudos de caso. Revista de Engenharia Sanitária e Ambiental 2003; 8 (2):25-38.

11. Brasil. M inistério da Saúde. Secretaria de Vigilância em Saúde. Coordenação Geral de Vigilância Ambiental. Indicadores de vigilância da qualidade da água de consumo humano - Relatório de Oficina de Trabalho. Brasília: Ed. Ministério da Saúde; 1999.

12. Last JM, organizador. A Dictionary of Epidemiology. New York: Oxford University Press; 1989.

13. Conway RA. Introduction to environmental risk analysis. In: Conway RA, organizador. Environmental Risk Analysis for Chemicals. New York: Ed. van Nostand Reinhold Company; 1982. p. 1-30.

14. Castiel LD. Vivendo entre exposições e agravos: a teoria da relatividade do risco. História, Ciências, Saúde - M anguinhos 1996; 3 (2): 237-264. 
15. Czeresnia D. Ciência, técnica e cultura: relações entre risco e práticas de saúde. Cad. Saúde Pública 2004; 20 (2):447-455.

16. Brasil. M inistério da Saúde. Diretrizes para o trabaIho em contenção com material biológico. Brasília: Ed. Ministério da Saúde; 2004.

17. World Health Organization. Sick Building Syndrome. Genebra: OM S. [acessado 2005 Mar 20]. Disponível em: http://www.who.inst/csr/don 2003 04 26/en/

18. La Rovere $\mathrm{E}$, et al. Indicadores de gestão ambiental municipal. Versão preliminar do relatório do PADCT/LIM A/COPPE/UFRJ, Rio de Janeiro; 1994.

19. Brasil. Ministério da Saúde. IDB 97 Brasil - Indicadores e dados básicos, Rede Interagencial de Informações para a Saúde/RIPSA, Braślia; 1998.

20. Brasil. M inistério das Cidades. Secretaria Nacional de Saneamento Ambiental. SNIS - Sistema Nacional de Informações sobre Saneamento. Diagnóstico dos Serviços de Água e Esgoto. Brasília; 2002.

21. Cities Environment Reports on the Internet. Urban Sustainability Indicators for the Improvement of Living and Working Condition; 1998.

22. Instituto Brasileiro Geografia e Estatística (IBGE). Indicadores Sociais M ínimos; 2004. [acessado 2004 Nov 20]. Disponível em: http://www.ibge.org/informações/indicadoresmínimos/indicador.htm
23. Organización Panamericana de la Salud (OPS). Situación de salud en las Americas: indicadores básicos 1998.

24. The World Bank. World Development Indicators. Washington: The World Bank; 2003.

25. United Nations Human Settlements Programme. Un-habitat. UNCHS, Urban Indicators Guidelines: Better Information for Better Cities. EEA Indicator Set; 2001. [acessado $2005 \mathrm{M}$ ar 20]. Disponível em: http://www.urbanobservatory.org/indicators/guidelines/ extended//

26. World Health Organization. División de promoción y protección de la salud. Organización Panamericana de la Salud. Oficina Sanitária Panamericana. Oficina Regional de la Organización Mundial de la Salud. Indicadores de salud y bienestar en municípios saludables. Washington, DC; 1994.

27. Massei W. Indicadores sociais e cidades saudáveis. I Oficina de Trabalho, Campinas; 1999.

28. World Health Organization. Environmental Health Indicators for Europe - A Pilot Indicator-Based Report. Denmark: WHO Regional Office for Europe; 2004.

Artigo apresentado em 06/03/2006

Aprovado em 31/05/2006

Versão final apresentada em 31/05/2006 